\title{
Prevalence and Abortion Methods Employed by Women Working in Flower Farms of Batu Town, Ethiopia
}

\author{
Desalegn Bekele ${ }^{1,}$,, Mohammed Taha ${ }^{2}$, Fasil Tessema ${ }^{2}$ \\ ${ }^{1}$ School of Medicine, Dire-Dawa University, Dire-Dawa, Ethiopia \\ ${ }^{2}$ Department of Epidemiology and Biostatistics, College of Public Health \& Medical Sciences, Jimma University, Jimma, Ethiopia
}

Email address:

desalegn333@gmail.com (D. Bekele), tahamohammed2009@gmail.com (M. Taha), alazarfasil@yahoo.com (F. Tessema)

\section{To cite this article:}

Desalegn Bekele, Mohammed Taha, Fasil Tessema. Prevalence and Abortion Methods Employed by Women Working in Flower Farms of Batu Town, Ethiopia. Science Journal of Public Health. Vol. 3, No. 3, 2015, pp. 404-409. doi: 10.11648/j.sjph.20150303.26

\begin{abstract}
Background: Each year, throughout the world, approximately 210 million women become pregnant and among these, 75 million pregnancies end in stillbirth, or spontaneous or induced abortion. This study was aimed to assess the prevalence of abortion, its associated factors and preferences of health care usage among women of reproductive age working in flower farms of Batu town, Oromia Regional State, Ethiopia. Methods: Institutional based cross sectional study was conducted from May 10 to 25, 2012 on 345 women of reproductive age who had history of pregnancy in the last six years while working in flower farms of Batu town. The study subjects were selected by simple random sampling. The data were collected by interviewer administered questionnaire for quantitative method. Quantitative data were coded and entered into and analyzed using SPSS for windows version 16.0. Binary logistic regression was done to test association between selected independent variables and outcome variable. Results: Abortion was reported by $87(25.6 \%)$ of those women. Out of these, $34(39.1 \%)$ were induced and 53(60.9\%) spontaneous abortion. Women whose last pregnancy were unwanted were about 7.9 times more likely to have an abortion than those women whose last pregnancy were wanted $(\mathrm{AOR}[95 \% \mathrm{CI}]=7.9[2.3,26.8])$. Women who had two and above births in the last six years were more likely to have an abortion compared to women who had one birth (AOR $[95 \% \mathrm{CI}]=4.9[2.3,10.7])$. Conclusions: Having more births in the last six years and having the last pregnancy unwanted were predictors of abortion in this study. Reaching more target group in encouraging women to utilize family planning especially condom and seek appropriate health care when it is needed is recommended.
\end{abstract}

Keywords: Abortion, Preference of Health Care Usage, Flower Farms

\section{Background}

An estimated 43.8 million abortions occurred in 2008; about $86 \%$ of all abortions took place in the developing world. In this year, more than $97 \%$ of abortions in Africa were unsafe [1].

One in eight pregnancy-related deaths worldwide is caused by unsafe abortion [2]. Thirteen percent of all maternal deaths could be prevented by implementing appropriate post abortion care and helping couples obtain family planning information and services [3-5]. Preventing unplanned pregnancies alone could avert around one quarter of maternal deaths, including those that result from unsafe abortion [6].

Worldwide, births to unmarried adolescent mothers are far more likely to be unintended and those outside marriage are more likely to end in abortion. They are, therefore, more likely to suffer serious complications and even death [7-9].

The estimated abortion rate in 2008 was 38 per 1,000 women aged 15-44 in Eastern Africa, 36 in Middle Africa and 28 per 1,000 in Western Africa; virtually all of the procedures in these sub regions were unsafe [10]. In Africa, one in every 150 abortions leads to death, compared to one in every 85,000 procedures in the developed world [2].

Women faced with an unintended pregnancy often selfinduced abortions or obtain clandestine abortions from medical practitioners, paramedical workers, or traditional healers [3]. Undesired pregnancies and induced abortion due to sexual violence and interruption of family planning services are among underlying risk factors for maternal deaths and illness [4, 11-13].

As of 2008 estimate in Ethiopia, more than seven in 10 
women who want to avoid pregnancy either do not practice contraception or use a relatively ineffective traditional method [14]. Unsafe abortion was one of the top 10 causes of hospital admissions accounts for nearly $60 \%$ of all gynecologic admissions and almost $30 \%$ of all obstetric and gynecologic admissions [15].

About half of all health facilities in Ethiopia provide induced abortion services. However, the proportion is much higher for public hospitals $(76 \%)$ and private or nongovernmental organization (NGO) facilities (63\%) than for public health centers $(41 \%)$. These proportions are likely changing rapidly, as efforts are being made to expand abortion services in public facilities. Currently, private and NGO facilities provide the induced abortions [16].

The reason for teenage pregnancy and abortion varies from country to country and from region to region within the same country. Factors that are associated with teenage pregnancy and abortion include rapid urbanization, low socioeconomic status, low access to contraceptive, low educational and career aspiration, residence in a single parent home and poor family relationship [17].

Due to the expansion of flower farm industries in Ethiopia in which the majority of the workers are women of reproductive age exposed to sexual risk behaviors, little was known about the magnitude of abortion and its associated factors. The problem of abortion and the preference of careseeking behavior among women working in flower farm areas (particularly, in the Batu town) have not been assessed. It was necessary and timely to study this important issue on women working in flower farms. This study was therefore aimed at investigating the prevalence of abortion, its associated factors and preference of health care usage among child-bearing women in flower farms.

\section{Methods}

\subsection{Study Area and Period}

Institutional based cross-sectional study design was employed from May 10 to 25, 2012 in flower farms of Batu town, which is located $169 \mathrm{~km}$ from Addis Ababa along the main road connecting Addis Ababa to Hawasa in the East Shewa Zone of Ethiopia. Adjacent to Lake Ziway, the economy of the town is based on fishing and horticulture [18] There are five flower farms around Batu town, namely Share Ethiopia, Ziway Rose, Herberg Rose, Braam Rose and AQ Rose; all are situated in the Southern part of the town having: - 2654, 1268, 1099, 508 and 1249 workers respectively. Out of these, 1956, 965, 766, 375 and 900 were childbearing women found in the respective flower farms. This means a total of 4,962 women in the flower farms were in child bearing age [19].

\subsection{Source Population}

Before the actual study, census was conducted for nine days to get the number of women who have ever been pregnant in the last six years. During the census, interview using short listed questionnaire was applied to get the total number of women experienced pregnancy. It was found that 1,732 women had experienced pregnancy at least once in the last six years.

The study population was selected women in the reproductive age group who had history of pregnancy in the last six years while working in the flower farms.

\subsection{Sample Size and Sampling Procedures}

The sample was estimated using sample size determination formula, $\left[\mathrm{n}_{\mathrm{o}}=(\mathrm{Z} \alpha / 2)^{2} \mathrm{p}(1-\mathrm{p}) / \mathrm{d}^{2}\right]$ for single population proportion using the following assumptions. A prevalence level of $(50 \%)$ for abortion; and desired precision of 5\%, 95\% confidence level and 10\% non-response rate were considered. Hence, the sample size was calculated as $\left[n_{o}=(Z \alpha / 2)^{2} \mathrm{p}(1-\mathrm{p})\right.$ $\left./ \mathrm{d}^{2}\right]=(1.96)^{2} \times(0.5 \times 0.5) /(0.05)^{2}=384$. Since the source population was less than 10,000 , the correction formula to estimate final sample size $\left(\mathrm{N}_{\mathrm{f}}\right)$ from finite source population $(\mathrm{N}=1,732)$ was employed.

$$
\mathrm{Nf}=\mathrm{n}_{\mathrm{o}} /\left(1+\mathrm{n}_{\mathrm{o}} / \mathrm{N}\right)=384 /(1+384 / 1732)=314
$$

With $10 \%$ non-response rate the final sample size was 345 women.

Simple random sampling was used in selecting the study subjects. All five flower farms of Batu town were stratified by their farm names (Share Ethiopia, Ziway Rose, Herberg Rose, Braam Rose and AQ Rose) and the flower farms were the strata in which study subjects were selected. Number of study subjects who fulfilled inclusion criteria in each flower farms was proportional to population sample size and was selected by simple random sampling using the list of women identified during census as sampling frame.

To strengthen quantitative data, 15 in-depth interviews were conducted with key informants, who have worked in the flower farms at least for the last six months and whose their position were department head or staff of health clinics in the flower farms.

\subsection{Data Collection Procedures}

Structured and pre-tested questionnaire was prepared first in English and then translated into local language (Amharic and Afan Oromo) for quantitative data collection. Five female diploma nurses conducted face to face interviews and one BSc. nurse supervised the data collection process. Training was given to the data collectors (Nurses) and supervisor on the aim of the study, data collection tool and art of interviewing. Semi-structured interviewer guide were used to collect data from head of health clinics and were tape recorded.

\subsection{Data Processing and Analysis}

Quantitative data were analyzed using SPSS for windows version 16.0. Descriptive statistics were done using frequencies and proportions in tables and figures. Binary logistic regression was also done to test association between selected independent variables and the outcome variable. P- 
value of less than 0.05 was used to declare statistical significance.

Qualitative data were transcribed \& summarized in to themes and analyzed manually. The results were presented in narratives triangulated with the quantitative results.

\subsection{Ethical Considerations}

Ethical clearance was obtained from Jimma University, College of Public Health and Medical Sciences, Ethical Clearance and Review Committee. Official permissions and letter of cooperation were obtained from the respective Batu flower farms. Study subjects were informed about the purpose of the study, their right to refuse and to withdraw. Written consent was obtained from each study subjects before the data collection and audio was recorded.

\section{Results}

\subsection{Socio-Demographic Characteristics}

From a total of 345 women who were identified for the study, 340 were participated in the study yielding the response rate of $98.6 \%$. Five incomplete questionnaires were removed from the analysis.

More than half of the respondents 198(58.4\%) were found between the age group of 20-24 years. The mean age of the respondents was 24.5years $(\mathrm{SD}=5.042)$. Large number of the respondents were Orthodox Christian 144(42.4\%), while $232(68.2 \%)$ of the respondents were married, $75(22.1 \%)$ were never married. The educational status of the large number of the respondents was grade 5-8 138(40.6\%). Monthly income of half of the respondents $183(53.8 \%)$ were between 551-600 Birr.

\subsection{Experience of Abortion}

Among a total of 340 women who were participated in the study, 250(73.5\%) respondents had one pregnancy. Out of those who were pregnant, 53(15.6\%) of the respondents reported as their last pregnancy were unwanted. From those women who ever pregnant in the last six years, 68(20.0\%) of them were not had history of birth. From those who ever had birth, $70(25.7 \%)$ of them had more than two births. Of all respondents, only 135(39.7\%) were ever used contraceptive. In this study, abortion was reported by $87(25.6 \%)$ from those who were ever pregnant women in the last six years. Out of those women who reported abortion, 54(62.1\%) and 33(37.9\%) of them had their abortion at gestational age below three months and above three months, respectively. Around 27(79.4\%) of induced abortion reported by the respondents were due to unwanted pregnancy. Among the reasons given by the respondents for induced abortion were pre-marital pregnancy 11 (32.4\%) and did not want more children 14(41.2\%) (Table 1).
Table 1. Pregnancy and abortion experience of women working in flower farms of Batu town, Ethiopia, May 2012.

\begin{tabular}{l|l|l}
\hline Variables & Number & $\%$ \\
\hline $\begin{array}{l}\text { Pregnancy terminated before } 28 \\
\mathrm{n}=340\end{array}$ & 87 & weeks of gestation in the last six years: \\
Yes & 253 & 74.4 \\
\hline No & 54 & \\
\hline Gestational Age abortion takes in the last 6 yrs : $\mathrm{n}=87$ & 62.1 \\
\hline$<3$ months & 33 & 37.9 \\
\hline 3 months & 34 & 39.1 \\
\hline $\begin{array}{l}\text { Type of Abortion: } \mathrm{n}=87 \\
\text { Induced }\end{array}$ & 53 & 60.9 \\
\hline Spontaneous & & \\
\hline
\end{tabular}

This is also supported by in-depth interview obtained from 32 years old women who has worked in the flower farm clinic for more than three years. She reported that sometimes pregnant women come to their clinic and ask for the procedures to terminate the pregnancy. She said: "when we tell them to think and change their decision, they will not come again to us. We understood later as they terminate the pregnancy in the community."

Another 29 years old women working in the flower farm clinic noted that abortion is recognized as major problem in Batu flower farms. She stressed that the problem is more prevalent among unmarried young girls. She said: ".....Majority of the girls comes from rural areas of the country and when they arrive to Batu town, they start and practice unsafe sex with more than one man. Women prefer to interrupt the pregnancy than to have a child if it is unwanted. We hear such information directly or indirectly during 'acha le acha'/peer group discussion on coffee ceremony with the female flower farm workers."

\subsection{Preferences for Health Care Usage among Women}

Those women who had induced abortion in the last six years were also asked for the place they had induction and $11(32.4 \%)$ of the respondents had their induction at their own house. Induction performed by traditional healers accounts to $16(29.4 \%)$. This result can be supported by in-depth interview. "...Sometimes women come to our clinic with different health problems including post abortion complications. When we assess and ask for the main cause for the problem, they told us as they had abortion somewhere else at the house of traditional healers or private clinics" indepth interviewee said.

But above $70 \%$ of the respondents, $67(77.0 \%)$ who experienced abortion visited modern health institution for post abortion services. The preferences of health facilities visited for post abortion care by those women who had abortion were health center 17 (25.4\%), clinic 31(46.3\%), and hospital 19(28.4\%)(Table 2). 
Table 2. Preferences of health care usage for induced abortion and PAC among women working in flower farms of Batu town, Ethiopia, May 2012.

\begin{tabular}{lll}
\hline Variables & Number & \% \\
\hline Preference of health care for abortion: $\mathrm{n}=34$ & & \\
Health facility & 15 & 44.1 \\
At home & 11 & 32.4 \\
At home of the abortionist & 8 & 23.5 \\
Other people helped that induced abortion $\mathrm{n}: 34$ & & \\
Traditional abortionist & 10 & 29.4 \\
Themselves & 8 & 23.5 \\
Health professional & 16 & 47.1 \\
Visit modern health institution for PAC: $\mathrm{n}=87$ & & \\
Yes & 67 & 77.0 \\
No & 20 & 23.0 \\
Type of modern health institution visited: $\mathrm{n}=67$ & & \\
Health center & 17 & 25.4 \\
Clinic & 31 & 46.3 \\
Hospital & 19 & 28.4 \\
\hline
\end{tabular}

\subsection{Factors Associated with Experience of Abortion}

As indicated in Table 3 only age group, marital status, work years in the farm and last pregnancy wanted were found to be statistically significant in bivariate analysis. When controlled for potential confounders, women whose their last pregnancy were unwanted were about 7.9 times more likely to have an abortion than those women whose their last pregnancy were wanted (AOR $[95 \% \mathrm{CI}]=7.9[2.3,26.8])$. Similarly, women who had two and above births in the last six years were more likely to have an abortion compared to women who had one births in the last six years (AOR [95\% $\mathrm{CI}]=4.9[2.3,10.7])($ Table 3$)$.

Table 3. Bivariate and multivariate analysis of factors associated with experience of abortion among women working in flower farms of Batu Town, Ethiopia, May 2012.

\begin{tabular}{|c|c|c|c|c|c|}
\hline \multirow{2}{*}{ Variables } & \multicolumn{2}{|c|}{ Experience of Abortion } & \multirow[t]{2}{*}{ COR (95\% C.I.) } & \multirow[t]{2}{*}{ P-value } & \multirow[t]{2}{*}{ AOR (95\%C.I.) } \\
\hline & $\operatorname{Yes}(n=87)$ & No $(n=253)$ & & & \\
\hline Age group & & & & 0.030 & \\
\hline $15-24$ & $63(23.1)$ & $210(76.9)$ & $0.3(0.1,0.8)^{*}$ & 0.013 & $0.2(0.02,1.6)$ \\
\hline $25-34$ & $16(30.8)$ & $36(69.2)$ & $0.4(0.1,1.3)$ & 0.115 & $0.5(0.04,5.0)$ \\
\hline $35-44$ & $8(53.3)$ & $7(46.7)$ & 1 & & 1 \\
\hline Marital status & & & & 0.007 & \\
\hline Never married & $25(33.3)$ & $50(66.7)$ & 1 & & 1 \\
\hline Married & $47(20.3)$ & $185(79.7)$ & $0.5(0.3,0.9)^{*}$ & 0.021 & $0.7(0.2,2.6)$ \\
\hline Divorced & $10(47.6)$ & $11(52.4)$ & $1.8(0.7,4.9)$ & 0.233 & $0.5(0.05,5.5)$ \\
\hline Widowed & $5(41.7)$ & $7(58.3)$ & $1.4(0.4,5.0)$ & 0.574 & $0.1(0.01,4.5)$ \\
\hline Work years in the farm & & & & 0.047 & \\
\hline$=<2$ years & $23(20.0)$ & $92(80.0)$ & $0.4(0.2,0.9)^{*}$ & 0.015 & $0.7(0.2,3.3)$ \\
\hline $3-4$ years & $37(24.7)$ & $113(75.3)$ & $0.6(0.3,1.1)$ & 0.077 & $0.9(0.3,3.0)$ \\
\hline $5-6$ years & $27(36.0)$ & $48(64.0)$ & 1 & & 1 \\
\hline Ever use of contraceptives & & & & 0.160 & \\
\hline Yes & $29(21.5)$ & $106(78.5)$ & 1 & & 1 \\
\hline No & $58(28.3)$ & $147(71.7)$ & $1.4(0.9,2.4)$ & & $0.5(0.2,1.5)$ \\
\hline Last pregnancy wanted & & & & 0.001 & \\
\hline Yes & $57(19.9)$ & $230(80.1)$ & 1 & & 1 \\
\hline No & $30(56.6)$ & $23(43.4)$ & $5.3(2.8,9.7)^{*}$ & & $7.9(2.3,26.8)^{* *}$ \\
\hline No of births in the last 6 yrs & & & & 0.002 & \\
\hline One & $19(9.4)$ & $183(90.6)$ & 1 & & 1 \\
\hline Two \&above & $20(28.6)$ & $50(71.4)$ & $3.9(1.9,7.8)^{*}$ & & $4.9(2.3,10.7)^{* *}$ \\
\hline
\end{tabular}

$*=$ Statistically significant at $\mathrm{p}<0.05$

$* *=$ Statistically significant at $\mathrm{p}<0.05$ when adjusted for other variables

\section{Discussion}

In this study, abortion was reported by $25.6 \%$ of those pregnant women. Another study done in maternal health review in Uganda showed that approximately $15-23 \%$ of female youths 15-24 years of age who had ever been pregnant had an abortion [20]. The difference might be due to the fact that this study included all reproductive age groups (15-49) while study in Uganda was on youth (15-24 years). The findings of this study are also comparable with many studies done in Ethiopia. The first one is study done in three regional state of Ethiopia, which overall $15.1 \%$ of the respondents were had at least one abortion episode [21]. The second is study done in northwest of Ethiopia in which $19 \%$ of the respondents have had abortions [22]. But, the prevalence of abortion in this study is higher than all of the studies aforementioned. The difference might be due the fact that in this study, the study subjects were female reproductive age who might have not get access to contraceptive or exposed to chemicals during flower production, which leads 
to unwanted pregnancy and abortion respectively.

In this study, no association was found between experience of abortion as educational status of women increased or decreased which is in line with study done in Harar [22], in which education did not have significant association with induced abortion.

As the finding of this study, women whose last pregnancy were unwanted were more likely to have an abortion than those women whose last pregnancy were wanted, which is similar with the report of study done in Ethiopia in which women with no history of unwanted pregnancy were less likely to report abortion in the past [21]. This shows as unwanted pregnancy is a main reason for women to experience an abortion.

According to the finding, $39.7 \%$ of the respondents were ever used contraceptive which is comparable with studies done in Harar in which ever use of modern contraceptive was found to be $25.7 \%$ among the sexually active group [23]. The slight differences might be due the fact that in this study, respondents are those women who ever experienced one or more pregnancy and expected to have high exposure to contraceptive use than sexually active group.

The study also revealed that women with high number of parity were found to have association with experience of abortion which is in different with study done in northwest Ethiopia [22], in which increase in number of births, there were a decrease in the number of mothers who had abortion. The possible explanation for this could be the differences in study subjects.

In this study from those women who had induced abortion in the last six years, only $44.1 \%$ of the respondents had their abortion at health facility. This study is in line with study done in Northwest Ethiopia [22], in which induction was conducted at their own houses by $54.7 \%$ and at the abortionist house by $40.6 \%$. Another study is study done in Nigeria in close to $20 \%$ of the women carried out the abortions themselves [24]. This indicates that for one or many reasons majority of women who had induced abortion perform induction out of health facilities.

This study revealed that around $79.4 \%$ of induced abortions reported by the respondents were unwanted pregnancy which is in line with study done in Addis Ababa [25-26], in which unwanted pregnancy was the main reason given for undergoing induced abortion of about $95 \%$.

In this study the main reasons given by the respondents for induced abortion were pre-marital pregnancy $32.4 \%$ and did not want more children $41.2 \%$ which is similar with studies done in Nigeria and Northwest Ethiopia, in which the women gave reason for induction were bad timing was the most frequent, after which the most common reasons were the desire to remain in school, the high cost of having more children, and the feeling that the pregnancy was not socially acceptable [22, 24].

\section{Limitations of the Study}

The study suffers from the usual limitation of a cross sectional study in detecting causes and affect relationship. Moreover, the nature of the sensitivity of the issue (abortion) and past history on abortion might be affected by recall bias and underestimated the prevalence of abortion. However, numerous scientific procedures such as supervision, pretest of data collection tool, and adequate training of data collectors and supervisor were employed to minimize the possible effects.

\section{Conclusions}

According to this study finding, the prevalence of abortion among women working in flower farms of Batu town was $25.6 \%$. Percentage for spontaneous abortion is large in this study. The reason might be, women would like to report induced abortion as spontaneous abortion or due to the nature of work environment in which they might be exposed to different chemicals. Having more births in the last six years and having the last pregnancy unwanted were predictors of abortion in this study. Above half of the women in flower farms that had induced abortion were not used health facility for abortion.

Sexual and reproductive health education for newly employed workers may be helpful to create awareness and reaching more target group in encouraging to utilize family planning especially condom and seek appropriate health care when it is needed. Much more effort should be done in building the capacity and strengthening collaboration with traditional abortionist, health facilities, flower farms, governmental and Nongovernmental organization in improving accessibility of quality safe abortion services. The government of Ethiopia should also work in making contraceptive methods access for women to alleviate premarital pregnancy.

In addition, to quantify true magnitude of pregnancy and abortion, different strategy with different study design need to be conducted in this area.

\section{Acronyms and abbreviations}

\author{
NGO: Non Governmental Organization \\ PAC: Post Abortion Care \\ SPSS: Statistical Package for Social Science \\ WHO: World Health Organization
}

\section{Authors' Contributions}

DB has played a great role with regard to the conception, design, data collection, analysis, interpretation and wrote the draft manuscript. MT and FT has made a substantial contribution of the study concept and design, developed the research protocol, acquisition, data collection, analysis and interpretation of data and reviewed the draft and final manuscript for important content. All authors read and approved the final version of the manuscript. 


\section{Acknowledgments}

Our sincere thank goes to Jimma University, College of Public Health and Medical Sciences, Department of Epidemiology and Biostatistics for the approval of the ethical clearance and their technical support. We would also like to thank all managers of Batu flower farms and all those women who agreed to participate in this study including data collectors and supervisor.

\section{References}

[1] Sedgh G et al., Induced abortion: incidence and trends worldwide from 1995 to 2008. The Lancet, 2012; 379(9816):625-632.

[2] Unsafe Abortion: Global and Regional Estimates of the Incidence of Unsafe Abortion and Associated Mortality in 2008. Sixth Edition, Geneva, 2011.

[3] Grimes D., Benson J., Singh S., Romero M., Ganatra B., Okonofua F., Shah I. Unsafe Abortion: The Preventable Pandemic. The Lancet Sexual and Reproductive Health Series, October 2006.

[4] Where Are We Now? After ten years, there's good news and bad news in the drive to achieve ICPD goals, 2004.

[5] Abortion: Technical and Policy Guidance for Health Systems. World Health Organization 2003. Switzerlandhttp://www.who.int/reproductive-health/(accesable on December 2011)

[6] United Nations, the Millennium Development Goals Report. New York, 2007.

[7] Giving Girls Today and Tomorrow: Breaking the Cycle of Adolescent Pregnancy. New York: UNFPA, 2007.

[8] A.A. Shaheen, M. Diaaeldin, M. Chaaya and Z.EI Roueiheb. Unintended pregnancy in Egypt: Evidence from the national study on women giving birth. Eastern Mediterranean Health Journal, Vol.13, No.6, 2007.

[9] Mangiaterra V., Pendse R., McClure K. and Rosen J. MPS Notes: Department of Making Pregnancy Safer, WHO/HQ). Volume1, No.1 October 2008, 1-4.

[10] Abortion Worldwide: A Decade of Uneven Progress, New York: Guttmacher Institute, 2009.

[11] Meeting Women's Health Care Needs after Abortion Program .Frontiers in Reproductive Health Population Council. Washington, D.C. 20008 U.S.A.

[12] The Johns Hopkins and the International Federation of Red Cross and Red Crescent Societies. Public health guide for emergencies, 138-150.
[13] Gipson J., Koenig M., and Hindin M. The Effects of Unintended Pregnancy on Infant, Child, and Parental Health: A Review of the Literature. Studies in Family Planning 2008; 39[1]: 18-38.

[14] Benefits of meeting the contraceptive needs of Ethiopian women, In Brief, New York: Guttmacher Institute, 2010, No. 1.

[15] Federal Democratic Republic of Ethiopia Ministry of Health. Technical and procedural Guidelines for safe abortion services in Ethiopia. June 2006, Addis Ababa.

[16] Guttmacher Institute, Facts on Unintended Pregnancy and Abortion in Ethiopia. International Perspectives on Sexual and Reproductive Health, 2010, 36(1):6-15. April 2010, New York, USA.

[17] Adegbenga MS, Dipeolo M, Babalola S \& Otu DA. (2003). Reproductive knowledge, sexual Behaviour And contraceptive Use among Adolescents in Niger State of Nigeria. Afri J. Reprod Health, 7:36-48.

[18] Central Statistics Agency 2005 national statistics/accessed on January 2012.

[19] Rosters of Batu flower farm workers accessed on December 2011.

[20] Sengooba F. , Neema S., Mbonye A., Sentubwe O., Onama V. Makerere University Institute of Public Health Systems Development Program. Maternal Health Review Uganda Authors: HSD/WP/04/03 page-17.

[21] Melkamu Y., Betre M., Tesfaye S. Utilization of Post-abortion care services in three regional states of Ethiopia. Ethiop J Health Dev.2010; 24 Special Issues 1: 123-129.

[22] Senbeto E., Degu G.,Abesno N.,Yeneneh H. Prevalence and associated risk factors of Induced Abortion in northwest Ethiopia. Ethiop. J. Health Dev. 2005; 19(1): 37-44.

[23] Worku S., Fantahun M. Unintended pregnancy and induced abortion in a town with accessible family planning services. The case of Harar in Eastern Ethiopia. Ethiop, J. Health Dev.2006; 20(2) :79-83.

[24] Friday E., Clifford O., Bisi A., Daru P. H., Johnson A. Women's Experiences of Unwanted Pregnancy and Induced Abortion in Nigeria. University of Jos, November 1996.

[25] Tamire W., Enqueselassie F. Knowledge, attitude, and practice on emergency contraceptives among female university students in Addis Ababa, Ethiopia. Ethiop.J.Health Dev. 2007; $21 ;(2): 111-116$.

[26] Melkamu Y., Enquselassie F., Ali A., Gebresilassie H., Yusuf L. Fertility Awareness and Post-Abortion Pregnancy Intention in Addis Ababa, Ethiopia. Ethiop. J. Health Dev.2003; 17(3):167-174. 